\title{
Attitudes and Uses of Alternative Medicine by Physicians at a Pediatric Hospital in Mexico
}

\author{
Ricardo Gómez Martínez ${ }^{1}$, Cecilia Colunga Rodríguez ${ }^{1,2}$, Marisol Ulloa Carrillo, \\ Mercedes Gabriela Orozco Solis², Mario Ángel González²,3, Julio César Vázquez Colunga², \\ Claudia Liliana Vázquez Juárez ${ }^{2}$ \\ ${ }^{1}$ Pediatric Hospital of the National West Medical Center at the Instituto Mexicano del Seguro Social (Mexican \\ Social Security Institute, or IMSS), Guadalajara, Mexico \\ ${ }^{2}$ University Center for Health Sciences (CUCS), University of Guadalajara, Guadalajara, Mexico \\ ${ }^{3}$ University Center for Tonalá (CuTonalá), University of Guadalajara, Guadalajara, Mexico \\ Email: ccolungar@yahoo.com
}

Received 27 February 2016; accepted 18 June 2016; published 21 June 2016

Copyright (C) 2016 by authors and Scientific Research Publishing Inc.

This work is licensed under the Creative Commons Attribution International License (CC BY). http://creativecommons.org/licenses/by/4.0/

c) (i) Open Access

\section{Abstract}

Background: Several studies have described the physician's attitudes, perceptions, knowledge and experience about the complementary and alternative medicine (CAM), reporting among their results that these therapies are usually perceived as useful, which has favor the increase in its use and recommendation, both personally and in the medical practices. Despite the relevance that CAM has regained in the last years, in Mexico there are no studies developed about this topic nor in this population. Methodology: A descriptive and transversal study was developed. The participants answer a survey designed and validated for Mexican population $(\alpha=0.72)$. The survey was applied to the doctors in a pediatric tertiary care hospital, the survey included demographic data, history of personal use of CAM, recommendation to patients and attitudes towards CAM. Averages, standard deviations and association statistics $(\chi i 2)$ were calculated. Results: $A$ total of 249 physicians were included: $51 \%$ turned to CAM, primarily to treat acute conditions in a complementary manner to conventional treatment. A third of the participants recommended CAM to their patients. The use of CAM by the physician was the only factor related to their recommendation of these treatments. The most commonly used and recommended therapies by doctors were homeopathy and herbal medicine. $72 \%$ consider it useful to have knowledge in CAM and $67 \%$ want more information about these therapies. $51 \%$ agree that the CAM should be included in the medical career. Conclusions: Half of the respondents use CAM, and one-third recommend. The most used therapies were homeopathy and herbal medicine. Most doctors consider the knowledge about CAM useful and want to have more information, but only half of them agreed on its inclusion in the career of medicine. 


\section{Keywords}

\section{Attitudes, Uses, Alternative Medicine}

\section{Introduction}

According to the National Center for Complementary and Alternative Medicine (NCCAM) of the National Institutes of Health in the US, the Complementary and Alternative Medicine (CAM) is defined as "the set of various medical and health care systems, practices and products that are not considered part of conventional medicine today" (NCCAM, 1998). Such therapies are often used as a substitute for conventional medicine (e.g. using herbs instead of antidepressants), or in conjunction with traditional medical treatments (e.g. acupuncture with pain medications to help reduce pain) (Kemper, Vohra, \& Walls, 2008).

The use of CAM as a treatment for different diseases is widely documented, examples include multiple sclerosis, heart disease, asthma, arthritis, skin conditions, among many others, where prevalence of use observed in patients ranges from 38.8\% to 80.9\% (Nicdao \& Ai, 2014; Adams et al., 2014; Babayigit, 2015; Basak, Unver, \& Demirkaya, 2014; Bilgili et al., 2014; Cheung, Geisler, \& Sunneberg, 2014). There is also evidence that CAM is used in the manner of complementary therapies in situations such as pregnancy, which is often used to control anxiety and stress (Frawley et al., 2014; Mitchell \& McCleanb, 2014).

In pediatric patients, the highest percentages of CAM use occur in children with chronic, recurrent or incurable diseases (Sanders et al., 2003; Kelly, 2004; Sibinga, 2006; Gomez, 2007). The motivations for its use are often multiple: parental dissatisfaction with the results of conventional medical treatment and its side effects, as well as the desire not to leave any resources without trying (Gagnon \& Recklitis, 2003).

Among physicians trained in conventional medicine, the CAM has gained acceptance over time, finding that these healthcare professionals keep increasing their levels of knowledge about this type of treatment. The CAM is often perceived as useful by doctors, this situation may be influencing the increase on the use and recommendation of such alternative treatments, both personally and in medical practice. It has been also observed a clear interest in having greater knowledge regarding this type of medicine among the physicians (Corbin \& Shapiro, 2002; Levine, Weber, \& Mayberry, 2003; Young \& Kyu Eun-Hee, 2008; Sierra, Urrego, \& James, 2012; Roy, Gupta, \& Ghosh, 2015). However, the perceptions, attitudes and experiences regarding the CAM among health professionals vary according to factors such as geographic location (Adams et al., 2013; Jupaneant et al., 2014; Roy, Gupta, \& Ghosh, 2015), the characteristics of the patients and the medical specialty practiced (Linde et al., 2015).

The CAM has become part of everyday practice of a wide variety of medical personnel. The attitudes that the medical personal has regarding the CAM influence the recommendation of such treatments as part of the medical care provided. However, despite the importance attached to the issue, to date, no study about the attitudes, use or CAM recommendations among physicians has been developed in Mexico.

Therefore, the main purpose of this research was to determine the use and attitudes about the utilization of CAM among doctors at a pediatric tertiary care hospital in Mexico, seeking to know the general perception they keep about such treatments as well as the personal and professional use granted to them in their daily lives.

\section{Research Setting}

According to the World Bank, in 2014 Mexico had a population of approximately 123 million people. Guadalajara, capital of Jalisco, is considered the second largest city in Mexico. In early 2015 the city recorded a population of 1,495,189 inhabitants (Ramírez, 2015).

In Mexico, only the people who work in the formal economy, whether they are active and retired, as well as their families, can be beneficiaries of the social security institutions that exist in the country, which provide service to approximately 48.3 million citizens, of whom about $80 \%$ are currently receiving care at the Instituto Mexicano del Seguro Social (Mexican Social Security Institute, or IMSS), one of the main institutions that make up the social security system in Mexico, responsible, among other things, for providing primary, secondary and tertiary health care services to its beneficiaries (Gómez et al., 2011).

This research was conducted in one of the facilities of this health institution, the Pediatric Hospital of the Na- 
tional West Medical Center, located in the city of Guadalajara, which has the second place in the country, because of the high level of specialty of the medical services provided and the amount of population attended, providing services to the pediatric population of eleven states of western Mexico. Currently, the hospital has a staff of 179 doctors between pediatricians and pediatric subspecialists, accompanied by 165 pediatric residents and students of different pediatric subspecialties.

\section{Methodology}

Participants were the physician working in the Medical Unit of High Specialty located at the Pediatric Hospital of the National West Medical Center. The sample included in this research was selected thru a simple random in consecutive cases sampling.

\subsection{Participants}

Define abbreviations and acronyms the first time they are used in the text, even after they have been defined in the abstract. Abbreviations such as IEEE, SI, MKS, CGS, sc, dc, and rms do not have to be defined. Do not use abbreviations in the title or heads unless they are unavoidable.

\subsection{Instrument}

The survey was design and previously validated for Mexican population $(\alpha=0.72)$ (Ulloa, 2015). It includes an initial section destined to gather demographic data: gender, age, type of role performed on the hospital (attending physician or resident), birthplace (rural or urban) and time of residence in the same location. The next section includes 18 questions, nine items destined to investigate about the use of CAM, including aspects such as the personal use, the type of illness for which they have used it, the frequency of use, the use compared to allopathic medicine, the illness for which they have recommended these treatments to their patients and the frequency of recommendation in the medical practice. The rest of the items talk about the attitudes towards CAM, asking if they have asked the parents of their patients if they are using CAM, whether they had recommended it in the medical practice, the perception about the safety of these treatments and the utility of having information about it, if they think that this alternative medicine should be included in the medical career, if they have received courses about these therapies and if they would like to have more information about CAM.

\subsection{Data Collection}

The procedures of this study were approved by the research ethics committee of the Hospital of Pediatrics of the National West Medical Center. Initially, the survey was distributed to the physicians at the hospital, during a regular work day, the participants were invited to participate in the study by the principal investigator. Verbal consent was obtained previously to the application of the survey, where it was explained the purpose of the investigation and that the participation on it would be voluntary, noting that refusing to be a part of the research would not affect its employment status in any way, also, the participants were told that the data obtained through the survey would be treated anonymously and confidentiality at all times, both during the analysis of the information obtained thru the research and in the products that could result from. The survey was answer manually, directly by the participants. The information obtained was captured in the electronic program Excel 2010, later the data was analyzed with IBM SPSS for Windows version 20.

\subsection{Data Analysis}

Averages and standard deviations were calculated for the sociodemographic variables. Frequencies and percentages were calculated for the use and attitudes variables. In the case of the last ones, the statistical difference between the answers was also calculated. Finally, the sociodemographic factors associated with the use and attitudes towards CAM were analyzed using $\chi 2$, were a value of $P<0.05$ was considered significant.

\section{Results}

\subsection{Sociodemographic Characteristics}

A total of 249 of the 253 surveys distributed were collected, of which 127 were attending physicians and 122 
medical residents. With regard to gender, $52 \%$ of respondents belonged to the male. The mean age was 35 years (standard deviation 8.5), with significant difference between attendings (mean 41.3, SD 7.5) and residents (mean 28.4, DS 2) $(P<0.000)$. Most doctors: 229 (92\%) were born in urban areas and 198 had live at least fifteen years on it.

\subsection{Personal Use and Patient Recommendation of CAM}

Of the 249 physicians surveyed, 127 (51\%) rely on CAM: 92 (72\%) to get treatment for acute illness, eleven (9\%) to manage chronic pain, eight (6\%) to address allergic conditions, and 5 (4\%) for chronic degenerative diseases. Most: 75/127 (59\%) use at least one form of CAM, and 112/127 (88\%) use them complementary to conventional medical treatment. No association was found between place of birth $(P=0.24)$, length of residence in the same place $(P=0.85)$ or role in the hospital $(P=0.1)$, with the personal use of CAM by the doctors (Table 1).

Of the total participants, eighty doctors (32\%) usually recommend CAM to their patients, mainly for treatment of acute conditions (43), chronic degenerative diseases (18), chronic pain (14) and allergies (10). Of these doctors, 52 (65\%) recommend at least one type of CAM, and 76/80 (95\%) do so in a complementary manner to conventional medical treatment. As is the case with the personal use of CAM, no association between the recommendation of these therapies and the birthplace of the physicians $(P=0.62)$, or its role in the hospital $(P=$ 0.27) was observed. The only factor associated with the recommendation of CAM to the patients was a history of personal use of these therapies $(P<0.000)$. The therapies used by doctors and recommended to patients are shown in Table 2.

\subsection{Attitudes about CAM}

The attitudes regarding CAM are presented in Table 2, where it is possible to observe that the only nonstatistically significant difference between the answers was found in the question about if they have asked the parents of their patients if they are using these treatments.

The discussion with parents about the use of these treatments in their patients was recognized for 127/249 (51\%) physicians. Talking about the safeness of these therapies, 57/249 (23\%) of the participants consider them safe, meanwhile, 180 (72\%) of the participants considered useful for their professional practice to have knowledge about CAM; and 166 (67\%) want to have more information about these therapies. Eighteen (7\%) have some therapy preparation on CAM. Finally, 128 (51\%) agree that CAM should be included in the curriculum of traditional medical career (Table 3).

\section{Discussion}

Although the use of CAM in Western culture has increased in recent decades, this is the first study performed in Mexico where it was possible to identify the perception that physicians in this country have about CAM and the use they give to these therapies both personally and professionally.

The most relevant results of the investigation revealed that the use of CAM among participating physicians is significant, highlighting the fact that almost $50 \%$ of the participants use these types of treatments personally, while roughly $30 \%$ recommend it to their patients within medical consultation.

This finding reveal that there is a high prevalence of personal use of CAM among doctors, very similar with the percentage reported by Sawni \& Thomas (2007), who found that $49 \%$ of the medical staff of a children's hospital

Table 1. Association between sociodemographic and work variables with the use and recommendation of CAM among the physicians.

\begin{tabular}{ccc} 
Variable & Use & Recommendation \\
\cline { 2 - 3 } & & $P$ value \\
Birth place & 0.24 & 0.62 \\
Time of residency in the same place & 0.85 & 0.50 \\
Role performed on the hospital & 0.10 & 0.27 \\
\hline
\end{tabular}


Table 2. Type of complementary and alternative medicine used and recommended by doctors.

\begin{tabular}{|c|c|c|c|c|}
\hline \multirow[t]{2}{*}{ Type of CAM } & \multicolumn{2}{|c|}{ Used } & \multicolumn{2}{|c|}{ Recommended } \\
\hline & $\mathrm{n}$ & $\%$ & $\mathrm{n}$ & $\%$ \\
\hline Homeopathy & 67 & 27 & 25 & 10 \\
\hline Herbalist & 55 & 22 & 32 & 12.8 \\
\hline Naturopathy & 25 & 10 & 12 & 4.8 \\
\hline Acupuncture & 12 & 4.8 & 6 & 2.4 \\
\hline Bach flowers & 8 & 3.2 & 8 & 3.2 \\
\hline Dietary supplements & 8 & 3.2 & 12 & 4.8 \\
\hline Magnet therapy & 7 & 2.8 & 1 & 0.4 \\
\hline Reflexology & 3 & 1.2 & - & - \\
\hline Acupressure & 3 & 1.2 & - & - \\
\hline Aromatherapy & 2 & 0.8 & 4 & 1.6 \\
\hline Massage therapy & 2 & 0.8 & 2 & 0.8 \\
\hline Mexican medicine & 2 & 0.8 & 2 & 0.8 \\
\hline Chinese medicine & 2 & 0.8 & - & - \\
\hline Diet & 1 & 0.4 & 6 & 2.4 \\
\hline Ozone therapy & 1 & 0.4 & 1 & 0.4 \\
\hline Yoga & 1 & 0.4 & 1 & 0.4 \\
\hline Heliotherapy & 1 & 0.4 & - & - \\
\hline Craniosacral therapy & 1 & 0.4 & - & - \\
\hline Moxibustion & 1 & 0.4 & - & - \\
\hline Chiropractic & 1 & 0.4 & - & - \\
\hline Music therapy & - & - & 1 & 0.4 \\
\hline
\end{tabular}

1) $n=$ frequency.

in Michigan reported being using CAM personally; other authors, had found higher rates of use, reporting that about $71 \%$ of the doctors in a pediatric hospital in Seattle are using some kind of CAM (Kundu, Tassone, Jimenez, Seidel, Valentine, \& Pagel, 2011). In Latin America, in an investigation carried out in Argentina it was reported that $13 \%$ of doctors in a pediatric hospital are using some form of CAM, while in another study conducted with doctors of 37 public hospitals in Colombia, it was found that $25 \%$ of the participants reported receiving some kind of alternative treatment (Brescia, 2004; Sierra, Urrego, \& James, 2012).

The acute conditions are the main reason for using CAM reported by the participating physicians, using it almost always as a complement to conventional medical treatment. Interestingly, the use of these therapies was not related to the history of birth in rural areas, or the residence time in it.

Another aspect studied in this research was the prevalence of CAM recommendation to patients in the medical practice, finding that a third part of the participants usually recommend these treatments to their patients, percentage lower than the observed on a study conducted in India, within a tertiary care hospital, where $52 \%$ of the participating physician recommend this type of treatment, a situation that could be due to the fact that CAM are more formally accepted and used from a long time ago in the eastern countries (Roy, Gupta, \& Ghosh, 2015).

It is noteworthy that the personal use of CAM was the only factor associated with the recommendation of these therapies within the medical practice, physicians that use this type of treatments were found five times more likely to recommend them to their patients, finding consistent with other studies that have found that the personal use of such therapies is a variable that has a direct influence on the recommendation of CAM in medical consultation, probably due to the influence generated by the experience (Young-Hee \& Eun Kyu, 2008; Sierra, Urrego, \& James, 2012; Roy, Gupta, \& Ghosh, 2015).

Although tradition may largely influence the types of CAM prevalent in a population at a given time, other factors such as economic globalization (Langwick, 2010; Leonti \& Casu, 2013) can influence the emergence of 
Table 3. Attitudes of physicians about Complementary and Alternative Medicine (CAM).

\begin{tabular}{|c|c|c|}
\hline Question & Total $n=249(\%)$ & $P$ \\
\hline \multicolumn{3}{|c|}{ Do you investigate the use of CAM? } \\
\hline No & $122(49)$ & \\
\hline Yes & $127(51)$ & 0.52 \\
\hline \multicolumn{3}{|c|}{ Are the CAM therapies safe? } \\
\hline Yes & $57(23)$ & \\
\hline No/I do not know & $192(77)$ & 0.000 \\
\hline \multicolumn{3}{|c|}{ Do you recommend CAM to your patients? } \\
\hline Yes & $80(32)$ & \\
\hline No & $69(68)$ & 0.000 \\
\hline \multicolumn{3}{|c|}{ Is useful to have knowledge about CAM? } \\
\hline Yes & $180(72)$ & \\
\hline No/I do not know & $69(28)$ & 0.002 \\
\hline \multicolumn{3}{|c|}{ Have you taken CAM therapies courses? } \\
\hline Yes & $18(7)$ & \\
\hline No & $231(93)$ & 0.026 \\
\hline \multicolumn{3}{|c|}{ Should CAM be included on the medicine career? } \\
\hline Yes & $128(51)$ & \\
\hline No/I do not know & $121(49)$ & 0.018 \\
\hline \multicolumn{3}{|c|}{ Do you want to have more information about CAM therapies? } \\
\hline Yes & $166(67)$ & \\
\hline No & 83 (33) & 0.004 \\
\hline
\end{tabular}

patterns not previously seen, or even the decreased use of others. In this research, the types of CAM most often used personally and professionally by doctors were homeopathy and herbal medicine, which might be due to the fact that both treatments have strong roots among the population: herbology has been practiced since pre-Hispanic times, and homeopathy is officially recognized since 1896 .

Moving on to talk about the attitude that physicians have about CAM, it was found that, just as Yasuhiro (2002) commented, there are polarized opinions about the alternative medicine, being possible to find two types of clearly defined perceptions about CAM among the participants, distinguishing between those doctors on favor of these kind of treatments, who often use and recommend these types of therapies, compared to the other group of physicians who do not usually use or recommend such therapies to their patients, however, it is important to acknowledge that despite the differences between both groups, most of the participants are currently investigating the use of CAM therapies in patients and about 51\% mentioned they had discuss about them with the parents of their patients. The main reasons for not recommending this type of therapy that the doctors have reported in other studies are the lack of time and knowledge about their effectiveness and safety, being an important point to take into consideration for future research (Roth et al., 2009).

The integration of alternative and conventional medicine has been promoted by WHO since the seventies, initially it was considered as an option for those countries or regions where the population's access to health services was poor, however, it has spread to developed countries quickly with the passage of time (Bell et al., 2002), observing that despite the disagreement that exists about the recommendation of CAM within the medical treatment, $67 \%$ of the participating physicians want more information regarding this type of alternative therapies and $51 \%$ believe that such treatment should be included in the medical career, a finding that is consistent with the observed before on several researches, which speaks about a latent interest regarding CAM in most of the doctors (Young \& Kyu Eun Hee, 2008; Sierra, Urrego, \& James, 2012; Roy, Gupta, \& Ghosh, 2015). 


\section{Conclusion}

In summary, talking about the use of this alternative medicine, the results indicate that near half of the participants use CAM personally, although the recommendation of such therapies in the medical practice is not reported that frequently, having the personal use as a factor associated to the recommendation of these treatments to the patients.

Regarding the attitudes, the CAM is considered as nonsafe therapies for the majority of the participants, however, it is important to notice that there is an interest in obtaining greater knowledge about these treatments and to include them in the medical career.

\section{Research Limitations and Implications}

The study results are limited only to physicians at a pediatric tertiary care hospital owned by a single Social Security Institution. Further research about this topic should include medical personnel from other specialties and health care institutions; so that way it is possible to know the perceptions and use of CAM in a larger population, in charge to provide attention to a wider variety of users in different contexts. Also it would be important to replicate this study with other health professionals, as those belonging to the nursing area, as they tend to keep more contact with patients.

However, despite these limitations, this study yielded important results that should be taken as a starting point for the generation of future research in both patients and health professionals, some of the most important are the high prevalence of CAM use among the medical staff of this hospital and the important influence that the personal experience with this type of therapy generates in the process of recommending these treatments to their patients in everyday practice.

\section{Conflict of Interest Declaration}

The authors declare that there is no conflict of interests related with this investigation, the authorship and/or the publication of this paper.

\section{References}

Adams, D., Dagenais, S., Clifford, T., Baydala, L., James, K., HervasMalo, M., Moher, D., \& Vohra S. (2013) Complementary and Alternative Medicine Use by Pediatric Specialty Outpatients. Pediatrics, 131, 225-232. http://dx.doi.org/10.1542/peds.2012-1220

Adams, D., Whidden, A., Honkanen, M., Dagenais, S., Clifford, T., Baydala, L., James, K., \& Vohra, S. (2014) Complementary and Alternative Medicine: A Survey of Its Use in Pediatric Cardiology. CMAJ Open, 2, 217-224. http://dx.doi.org/10.9778/cmajo.20130075

Babayigit, A. H. (2015). High Usage of Complementary and Alternative Medicine among Turkish Asthmatic Children. IranianJournal of Allergy, Asthma \& Immunology, 14, 410-415.

Basak, T., Unver, V., \& Demirkaya, S. (2014). The Use of Complementary and Alternative Medicine by Multiple Sclerosis Patients in Turkey. Gulhane Medical Journal, 56, 71-75. http://dx.doi.org/10.5455/gulhane.39346

Bell, I., Caspi, O., Schwartz, G., Grant, K., Weil, A. et al. (2002) Integrative Medicine and Systematic Outcomes Research: Issues in the Emergence of a New Model for Primary Health Care. Archives of Internal Medicine, 162, 133-140. http://dx.doi.org/10.1001/archinte.162.2.133

Bilgili, S., Ozkol, H., Karadag, A., \& Calka, O. (2014). The Use of Complementary and Alternative Medicine among Dermatology Outpatients in Eastern Turkey. Human \& Experimental Toxicology, 33, 214-221. http://dx.doi.org/10.1177/0960327113494904

Brescia, S. (2004). Actitud y Opinión de los Pediatras ante las Medicinas Alternativas. Archivos Argentinos de Pediatría, 102, 88-95.

Cheung, C., Geisler, C., \& Sunneberg, J. (2014). Complementary/Alternative Medicine Use for Arthritis by Older Women of Urban-Rural Settings. Journal of The American Association of Nurse Practitioners, 26, 273-280. http://dx.doi.org/10.1002/2327-6924.12063

Corbin, W., \& Shapiro, H. (2002) Physicians Want Education about Complementary and Alternative Medicine to Enhance Communication with Their Patients. Archives of Internal Medicine, 162, 1176-1181. http://dx.doi.org/10.1001/archinte.162.10.1176

Frawley, J., Adams, J., Broom, A., Steel, A., Gallois, C., \& Sibbritt, D. (2014). Majority of Women Are Influenced by Non- 
professional Information Sources When Deciding to Consult a Complementary and Alternative Medicine Practitioner During Pregnancy. Journal of Alternative \& Complementary Medicine, 20, 571-577.

http://dx.doi.org/10.1089/acm.2014.0028

Gagnon, E., \& Recklitis, C. (2003) Parents’ Decision-Making Preferences in Pediatric Oncology: The Relationship to Health Care Involvement and Complementary Therapy Use. Psychooncology, 12, 442-452. http://dx.doi.org/10.1002/pon.655

Gómez, O., Sesma, S., Becerril, V., Knaul, F., Arreola, H., \& Frenk, J. (2011) Sistema de salud de México. Salud Pública de México, 53, 220-232.

Gomez, R., Tlacuilo, A., \& Garibaldi, R. (2007) Use of Complementary and Alternative Medicine in Children with Cancer in Occidental, Mexico. Pediatr Blood Cancer, 49, 820-823. http://dx.doi.org/10.1002/pbc.21101

Jupaneant, O., Hegyi, G., Tudor, A., \& Dragan, S. (2014). Comparative Study on Complementary and Alternative Medicine (Cam) Use by Physicians in Romania and Hungary. Jurnalul Pediatrului, 17, 71-77.

Kelly, K. (2004). Complementary and Alternative Medical Therapies for Children with Cancer. European Journal of Cancer, 40, 2041-2046. http://dx.doi.org/10.1016/j.ejca.2004.05.012

Kemper, K., Vohra, S., \& Walls, R. (2008). The Use of Complementary and Alternative Medicine in Pediatrics. Pediatrics, 122, 1374-1387. http://dx.doi.org/10.1542/peds.2008-2173

Kundu, A., Tassone, R., Jimenez, N., Seidel, K., Valentine, J., \& Pagel, P. (2011). Attitudes, Patterns of Recommendation, and Communication of Pediatric Providers about Complementary and Alternative Medicine in a Large Metropolitan Children's Hospital. Clinical Pediatrics, 50, 153-158

Langwick, S. (2010). From Non-Aligned Medicines to Market-Based Herbals: China’s Relationship to the Shifting Politics of Traditional Medicine in Tanzania. Medical Anthropology, 29, 15-43. http://dx.doi.org/10.1080/01459740903517378

Leonti, M., \& Casu, L. (2013). Traditional Medicines and Globalization: Current and Future Perspectives in Ethnopharmacology. Frontiers in Pharmacology, 4, 1-13.

Levine, S., Weber, M., \& Mayberry, R. (2003). Complementary and Alternative Medical Practices: Training, Experience and Attitudes of a Primary Care Medical School Faculty. Journal of the American Board of Family Medicine, 16, 318-326. http://dx.doi.org/10.3122/jabfm.16.4.318

Linde, K., Alscher, A., Friedrichs, C., Wagenpfeil, S., Karsch, V., \& Schneider, A. (2015). Belief in and Use of Complementary Therapies among Family Physicians, Internists and Orthopaedists in Germany-cross-Sectional Survey. Family Practice, 32, 62-68. http://dx.doi.org/10.1093/fampra/cmu071

Mitchell, M., \& McClean, S. (2014). Pregnancy, Risk Perception and Use of Complementary and Alternative Medicine. Health, Risk \& Society, 16, 101-116. http://dx.doi.org/10.1080/13698575.2013.867014

National Center for Complementary and Alternative Medicine (NCCAM) (1998). General Information. Bethesda, MD, USA. http://nccam.nih.gov/health/whatiscam/

Nicdao, E., \& Ai, A. (2015). Religion and the Use of Complementary and Alternative Medicine (CAM) among Cardiac Patients. Journal of Religion \& Health, 53, 864-877. http://dx.doi.org/10.1007/s10943-013-9681-6

Ramírez, G. (2015). Jalisco. Gobierno del Estado. http://www.jalisco.gob.mx/es/jalisco/guadalajara

Roth, M., Lin, J., Kin, M., \& Moody, K. (2009). Pediatric Oncologists’ Views toward the Use of Complementary and Alternative Medicine in Children with Cancer. Journal of Pediatric Hematology/Oncology, 31, 177-182. http://dx.doi.org/10.1097/MPH.0b013e3181984f5a

Roy, V., Gupta, M., \& Ghosh, R. K. (2015). Perception, Attitude and Usage of Complementary and Alternative Medicine among Doctors and Patients in a Tertiary Care Hospital in India. Indian Journal of Pharmacology, 47, 137-142. http://dx.doi.org/10.4103/0253-7613.153418

Sanders, H., Davis, M., Duncan, B., Meaney, F., Haynes, J., \& Barton, L. (2003). Use of Complementary and Alternative Medical Therapies among Children with Special Health Needs in Southern Arizona. Pediatrics, 111, 584-587. http://dx.doi.org/10.1542/peds.111.3.584

Sawni, A., \& Thomas, R. (2007). Pediatricians’ Attitudes, Experience and Referral Patterns Regarding Complementary/Alternative Medicine: A National Survey. BMC Complementary and Alternative Medicine, 7, No. 18.

Sibinga, E., Sindell, D., Casella, J., Duggan, A., \& Wilson, M. (2006). Pediatric Patients with Sickle Cell Disease: Use of Complementary and Alternative Therapies. The Journal of Alternative and Complementary Medicine, 12, 291-298. http://dx.doi.org/10.1089/acm.2006.12.291

Sierra, S., Urrego, D., \& Jaime, J. (2012). Conocimientos, Actitudes y Prácticas Acerca De La Medicina Alternativa En Médicos Vinculados a Hospitales Públicos De Cundinamarca, Colombia (Spanish). Revista de Salud Pública, 14, 478490.

Ulloa, M. (2015). Usos y Recomendaciones de Medicina Alternativa por Parte de Médicos y Enfermeras de la UMAE, Hospital De Pediatría Del CMNO Del IMSS. Tesis de Especialidad Inédita, México: Instituto Mexicano del Seguro Social. 
Yasuhiro, S. (2002). WHO Global Strategy on Traditional and Alternative Medicine. Public Health Reports, 117, $300-301$.

Young-Hee, Y., \& KyuEun, L. (2008). A Comparison of the Knowledge of, Experience with and Attitudes towards Complementary and Alternative Medicine between Nurses and Patients in Korea. Journal of Clinical Nursing, 17, $2565-2572$. http://dx.doi.org/10.1111/j.1365-2702.2007.02065.x 